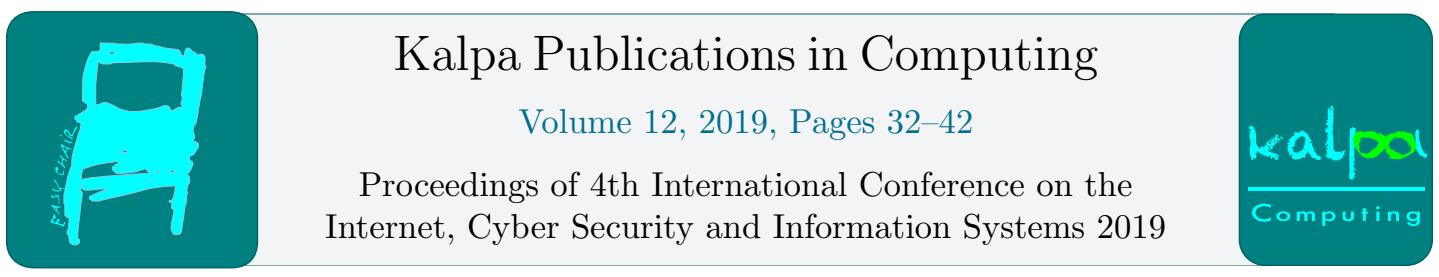

\title{
Understanding the role of ICT in South African Sustainable Manufacturing Practice (SMP)
}

\author{
Mohammed Alhassan ${ }^{1}$ and Brenda Scholtz ${ }^{2}$ \\ ${ }^{1,2}$ Department of Computing Sciences, Nelson Mandela University, Port Elizabeth, South Africa.
}

\begin{abstract}
Existing literature perceived Economic, Social and Environmental (ESE) factors as three key drivers of Sustainable Manufacturing Practice (SMP). ICT is not considered as a driving factor, but only as a tool that supports the achievement of SMP. The aim of this study is to investigate the role of ICT in achieving SMP in South Africa. A systematic literature review was conducted. The Google Scholar search engine was used to retrieve 1,352 articles that were analysed in this study. Themes and constructs were analysed based on the scope of the study. The findings revealed that South African manufacturing stakeholders are leveraging the advancement of ICT such as Artificial Intelligence and smart production systems to drive SMP through reduced waste and optimisation of resources. Also, the findings revealed that ICT plays a significant role that warrant its consideration as a fourth factor that drives SMP. This study emphasised the role of ICT as a driver in achieving SMP and presents the ESET model (ESE with the addition of Technology) to support the argument that ICT is a major driving factor for SMP. Understanding the role of ICT can influence how the issues of SMP are addressed and stakeholders can rethink strategies for SMP. Further empirical studies with a broader scope are encouraged because the review process and the scope of this study limits its generalisability
\end{abstract}

\section{Introduction}

The discourse on sustainable ecosystems emphasises how societies conduct affairs with stringent consideration to the environment [1]. The rising energy consumption, GHG and CO2 emissions, materials generated and increasing quantity of water usage in manufacturing industries have an impact on environmental degradation. The attainment of environmentally sustainable practices is a common concern amongst several disciplines. Green ICT initiatives and the use of ICT to minimise environmental pollution are strategies to achieving sustainable manufacturing practice (SMP) [2].

Individuals, businesses, and governments have been pressured to ensure environmental sustainability in every activity as a result of rising global warming, increasing climate change and degradation of ecosystems [3], [4]. The need for sustainable practice is changing how businesses 
operate. Businesses are concerned about how to strike a balance between the costs of operation and maintaining social righteousness. Manufacturing firms are worried about the best strategies to survive climate change concerns. These concerns pose significant challenges to how businesses make routine decisions to comply with the government's environmental policies and societal perceptions of SMP.

The South African manufacturing industry is a robust sector with the potential to compete in the global economy. Manufacturing organisations in South Africa play a pivotal role in stimulating the growth of other sectors, creating employment opportunities and economic empowerment [5]. The sector presents opportunities that significantly accelerate South African economic growth. South African industries are increasingly adopting sustainable initiatives by enforcing strategies that integrate SMP. South Africa is a signatory to the United Nations Global Compact (UNGC) and the majority of South African organisations are adopting the Global Reporting Initiatives (GRI) framework as an indication for transparency towards SMP [6].

Manufacturing organisations can use ICT to achieve SMP by initiating an operational and cultural shift that will eliminate the cost of commuting (telecommuting), introduce remote working (teleworking), and encourage companies to do business online. The use of an alternative e-market as a means of conducting business will reduce the emission of $\mathrm{CO} 2$ and decrease road traffic. In 2015, thirty South African Industrial Associations signed a voluntary Energy Efficiency Accord (EEA) to reduce energy consumption by $15 \%$. The ISO 14000 certificate was awarded to over 90 Fortune 500 companies that complied with strategies of reducing harmful effects [6]. These initiatives push organisations to monitor and uphold SMP. Industries are using manufacturing technologies driven by ICT to achieve SMP. The extent to which ICT is used to achieve SMP is sufficient to argue that ICT is not just a tool but a key driver to SMP.

The objective of this study is to understand the role of ICT in achieving SMP. This study argues that ICT is a key driver for SMP and not merely a tool for supporting SMP. Existing literature has not considered ICT as an SMP driver. This study addresses this gap by investigating recent ICT developments such as Artificial Intelligence (AI), Internet of Things (IoT) and smart systems and their role in SMP. The scope and context was focused on South African industries. A systematic literature review was adopted to understand the role South African industries are playing to achieve SMP and how ICT is influencing the sustainability paradigm shift. This paper is structured into four sections. The introduction and review methodology are described in the first and second sections respectively. The third section discusses the findings of the review and the last section presents the conclusions for this study.

\section{Review Method}

To achieve the objective of this study, a systematic literature review [7] was conducted to analyse existing relevant articles. This study limited its search to journal articles on Google Scholar because of the platform's reputation, wide coverage and robust searching algorithm. The literature search focused on three key terms: sustainable manufacturing; resource usage in manufacturing; and recycling and waste management in manufacturing industries. Almost $95 \%$ of articles selected for review were limited to publications between the years 2013 and 2018 because of the evolvement of the subject in the context of this study. The searching process returned 1,330 articles.

Further review was conducted by perusing the titles and abstracts of the articles returned to determine if the articles fits the research's goal. A total of 128 articles were documented after the selection and exclusion phase. Then, articles that focus on South Africa and relates to the three key research terms (that is waste management, resource optimization and ICT in sustainable manufacturing) were considered as relevant articles for review. Document scanning was the third review process in this study, and the content of each article was perused (two to five minutes on each article). 
Table 1 shows the list of major articles selected for detailed analysis $(n=30)$ and the results are discussed in more detail in Section 3. The thematic analysis approach recommended by [8] provided a detailed description of the strategy to identify, analyse and report constructs in this study. The Nvivo analytics tool was used to review and analyse articles. Table 1 list the articles reviewed in this study by authorship, year of publication and whether the paper addresses how technology is used for waste management, resource optimisation and the role of ICT in SMP. Since only 19 articles were found that referred to South Africa, the detailed analysis was expanded to those conducted in Southern Africa and Africa.

\begin{tabular}{|c|c|c|c|c|c|}
\hline Author & Year & $\begin{array}{c}\text { Waste } \\
\text { Management }\end{array}$ & $\begin{array}{c}\text { Resource } \\
\text { Optimisation }\end{array}$ & $\begin{array}{l}\text { Technology } \\
\text { Use }\end{array}$ & Context \\
\hline$[25]$ & 2017 & $\mathrm{x}$ & & & Southern Africa \\
\hline$[26]$ & 2017 & $\mathrm{x}$ & & & \\
\hline [27] & 2018 & $\mathrm{x}$ & $\mathrm{x}$ & & \\
\hline$[1]$ & 2015 & & $\mathrm{x}$ & & South Africa \\
\hline [13] & 2017 & & $\mathrm{x}$ & & \\
\hline [14] & 2013 & & & $\mathrm{x}$ & \\
\hline [15] & 2018 & & & $\mathrm{x}$ & \\
\hline [18] & 2017 & $\mathrm{x}$ & & $\mathrm{x}$ & \\
\hline [19] & 2017 & & $\mathrm{x}$ & & \\
\hline [19] & 2013 & & $\mathrm{x}$ & & \\
\hline$[2]$ & 2013 & & & $\mathrm{x}$ & \\
\hline$[20]$ & 2013 & & & $\mathrm{x}$ & \\
\hline$[21]$ & 2017 & & & $\mathrm{x}$ & \\
\hline$[22]$ & 2017 & & & $\mathrm{x}$ & \\
\hline$[24]$ & 2017 & & & & \\
\hline [29] & 2017 & & & $\mathrm{x}$ & \\
\hline [31] & 2017 & & $\mathrm{x}$ & $\mathrm{x}$ & \\
\hline [32] & 2017 & $\mathrm{x}$ & $\mathrm{x}$ & $\mathrm{x}$ & \\
\hline [33] & 2018 & & $\mathrm{x}$ & $\mathrm{x}$ & \\
\hline [34] & 2017 & & $\mathrm{x}$ & $\mathrm{x}$ & \\
\hline [5] & 2017 & $\mathrm{x}$ & $\mathrm{x}$ & $\mathrm{x}$ & \\
\hline [6] & 2007 & $\mathrm{x}$ & $\mathrm{x}$ & & \\
\hline [12] & 2018 & & & $\mathrm{x}$ & Africa \\
\hline$[16]$ & 2011 & & & $\mathrm{x}$ & \\
\hline [17] & 2012 & $\mathrm{x}$ & & & \\
\hline$[23]$ & 2018 & & & $\mathrm{x}$ & \\
\hline$[28]$ & 2017 & & & & \\
\hline
\end{tabular}


[3]

[30]
2015

2017

2016
$\mathrm{X}$

$\mathrm{X}$

[9] $\mathrm{X}$

Table 1: Articles selected for detailed analysis $(n=30)$

\section{Discussion}

\subsection{The Need for Sustainable Manufacturing Practice in South Africa}

Manufacturing industries contribute significantly to harmful emissions, environmental waste, resource depletion, emission of polymerised compounds and landfill combustion experienced globally [17], [24], [26]. Wastes such as plastic waste, landfill gas emission, spillage, and air pollution are common wastes that can easily be identified around us. From the literature reviewed it is evident that plastic waste, landfill waste and water pollution are the three major manufacturing wastes.

Plastic waste is the predominant manufacturing waste produced in South Africa [26]. Over 4\% of the annual petroleum production is converted directly into plastic products, and more than $50 \%$ of global plastic products are used to produce single-use disposable products and packaging, which often end up as solid waste [27]. Plastics are also used in automation and industrial manufacturing. The strength, low cost, robustness, design and fabrication flexibility are factors that drive the wide usage of plastics [25].

Landfill gas combustion is another waste and environmental pollutant that is a concern and requires appropriate disposal management [17], [26]. Combustion from landfills is prominent in South Africa. Waste from local manufacturing industries, households, and electronic waste are often thrown into a dumping site. Landfill and poor waste disposal are recorded in some South African townships. The practice of landfill dumping is prevalent in developing countries but less effort has been in place to tackle this menace. Few clean development projects to curb landfill combustion have been registered in African countries compared to other developing countries facing a similar issue [17]. Landfill gas emission produces leachates that degrade the soil, causes water pollution and emits carbon dioxide and methane that are harmful to the environment and human health. Some landfill wastes end up in water [10] and often cause water pollution, which has been associated with increased infant mortalities, skin lesion and respiratory distress, the death of aquatic animals and the lack of clean water for consumption and agriculture.

\subsection{Factors Driving Sustainable Manufacturing Practice}

Three factors of Economic, Social and Environment (ESE) were identified as the main drivers to SMP in prior studies [22], [25]. However, the review results revealed that the role of ICT is well highlighted in the literature as a tool rather than a driving factor for SMP. This study therefore argues that ICT is not just a tool as suggested in literature [32] but as a SMP driving factor, thus resulting in four factors driving SMP i.e. Economic, Social, Environmental and Technological (ESET).

a) Economic Factor: The economic factor is driven by customers' demands for sustainable products, desire for industries to attain competitive edge, cost reduction through recycling, energy insecurity concerns, increase scarce resources, and the rising cost of production. Most countries are driven by economic factors to adopt sustainable manufacturing [21], [22], [35]. Over the past ten years, companies are changing their business models to align with the global call for sustainability. Products are produced and labelled to indicate compliance with sustainable practices. Customers are also seeking products that are eco-friendly. Industries need to adopt resource-efficient strategies to remain competitive in the global market [18]. 
b) Social Factor: Social drivers are legislations and corporate responsibilities to meet the expectation of customers, society and government agencies. South Africa has often complied with international safety policies and environmental standards since the early stage of industrialisation [28]. African countries are obliged to adopt SMPs because they are signatories to global environmental treaties [24] such as the 2015 Paris COP 21, the International Labour Organisation convention and the United Nation's Sustainable Development Goals (SDGs). South African companies are taking proactive measures to initiate recycling of composites to manage wastes in line with international standards [21]. The government of South Africa is enforcing legislations such as landfill bans and restrictions, the deposit-refund strategy and extended producer responsibilities in regions with high plastic waste [27]. Increased human population has resulted in the increased demand for more resources, which is driving manufacturers to consider sustainable processes [25]. Societies are becoming more enlightened about the need to conserve resources to maintain ecological balance. The extent of public awareness on the need for sustainable practices is forcing industries to adopt eco-friendly manufacturing processes.

c) Environmental Factor: This study identified environmental concerns as one of the frontline drivers for SMP in South Africa. A detailed description of environmental factors that push South African industries to adopt sustainable manufacturing is presented in [25] and [32]. Environmental protection, global warming, a growing human population and climate change are the overreaching environmental factors for SMP. The long-term goal of SMP is to improve the current state of the environment and make it a better place.

d) Technological (ICT) Factor: In the era of digital manufacturing, industries are experiencing profound changes that integrate digital technologies in the manufacturing process [11]. Industries are forced to consider the application of contemporary technologies to adhere to sustainable practices, optimise production processes, reduce the cost of production, and to build a reputation for their firms. Demand for new products have increased, which is forcing manufacturers to introduce technologies that help manufacturer make intuitive decisions that guarantees sustainability (for example smart systems and intelligent technologies) [33]. Industries are integrating technologies like smart grid and intelligent energy monitoring systems to manage energy usage in manufacturing industries [32], [35]. The transformation in the manufacturing sector has resulted in the emergence of "Industry 4.0", "factory of things", "smart factory", and "real-time production" [11].

\subsection{Role of ICT in Sustainable Manufacturing Practice}

To understand the role of ICT in driving SMP, it is pertinent to know what are the perspectives to SMP. This section describes how ICT is driving industries to achieve SMP. The overarching goal for SMP in this study is classified into two main categories, namely: (i) Waste management and recycling and (ii) Resource optimisation. 


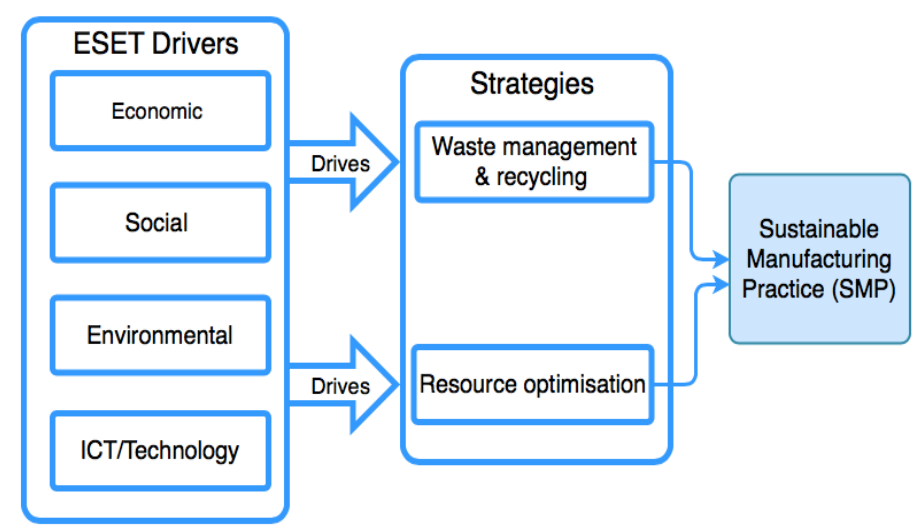

Figure 1: Proposed ESET Model of SMP Drivers

Figure 1 illustrates the proposed ESET model of four drivers of SMP, which shows the relationship between ICT, SMP strategies and SMP. The arrow from ICT/Technology into resource optimisation and waste management shows how ICT is driving stakeholders to implement SMP strategies.

\subsubsection{Waste Management and Recycling as SMP}

SMP is the utilisation of used materials or post-consumed resources as raw materials to produce new products thereby reducing the exhaustive use of new resources (like raw materials, energy, water) and minimising pollution. Recycling is the process of keeping resources for as long as possible to extract the maximum value [21]. In other words, recovering and regenerating materials after each end of service life. Over 30\% of the articles reviewed argued that plastic waste is a major bottleneck to sustainability in South Africa. Recycling is the most effective environmentally friendly strategy to recover polymers and used plastic materials, which will reduce carbon dioxide emission, curb oil usage and reduce a large amount of disposed solid waste [25].

The recycling of waste materials to achieve sustainability is a national priority for developing countries [22]. South African institutions realised that the most sustainable way of removing industrial waste from urban communities is to actively scavenge recyclable waste from door to door, substitute fertilisers with maturated compost and disposal of biogenic waste [17]. South African industries are not actively developing strategies that will lower carbon emission or enforcing the process of remanufacturing of retired products [21]. Waste management and recycling are effective means of achieving SMP because it closes the manufacturing cycle with the possibility of attaining $100 \%$ efficiency [18]. 


\subsubsection{Resource Optimisation as SMP}

The proponents of SMP as a means of conserving ecological resources view sustainable manufacturing as a production process that utilises non-polluting resources and economically viable processes. This approach to SMP will conserve energy, natural resources, provide a conducive working environment for employees, and offer sustainable products [24]. The United Nation's definition of sustainability is focused on conserving and preserving resources. The United Nations describes sustainability as a development strategy that meets the needs and aspiration of the present without compromising the ability of future generations in meeting their own needs [13]. Economic efficiency, social equity and environmental responsibility are the three driving values of sustainability [11]. Environmental value focuses on the reduction of gas emission, elimination of substances that deplete the ozone layers, protection of biodiversity, and optimisation of the use and management of energy. Social value improves the working and social conditions of all stakeholders. Economical value increases the efficiencies in companies, promotse best practice in production processes and the introduction of eco-friendly innovations.

ICT plays an important role in achieving and driving SMP in South African industries. Several types of ICTs are been used by manufacturing companies in South Africa to achieve SMP through the implementation of self-sustaining technologies that do not compromise the abilities of future generations to achieve their needs [29]. The interaction of digital technologies like AI, ubiquitous manufacturing systems, cloud computing, IoT and ICT infrastructure to advance manufacturing processes and maximise resources [12], [32]. These initiatives are possible with the development of new digital manufacturing platforms.

\begin{tabular}{lll}
\hline Type of ICT & Examples & SOURCE \\
\hline Artificial intelligence (AI) & Robotics & {$[12],[32]$} \\
& Decision Support Systems & {$[11],[33]$} \\
\hline Smart production systems & 3D printing & {$[12],[33]$} \\
& Network technology & {$[31]-[33]$} \\
& IoT driven & {$[16],[31]$} \\
\hline
\end{tabular}

Table 2: Types of ICT used for SMP in South Africa

Sustainable manufacturing supports value creation based on a distributed manufacturing process. Manufacturing industries in South Africa are undergoing a technological transformation. AI, and smart production systems were the two leading ICT/technological interventions identified from the review conducted in this study. Examples of these interventions are summarised in Table 2. From the review it was evident that ICT plays a role in South African's SMP by influencing sustainable strategies and supporting the attainment of sustainable goals.

Some South African industries are using controlled and reprogrammable manipulators to automate production activities. The automotive, electronics, plastic and metal production industries are the predominant users of robotics in South Africa [32]. The introduction of technology in modern manufacturing is considered the 4th industrial revolution (Industry 4.0). Industry 4.0 offers a new era of opportunity to achieve environmentally sustainable manufacturing and efficient resource utilisation [33].

The application of AI is driving industries to achieve flexibility and resource efficiency. Systems are built to develop intelligence capabilities to support and make critical manufacturing decisions. The predictive maintenance system used in some South African industries is an example of a modern production practice. A predictive system can automatically notify factory workers to replace worn out parts or predict avert machine break down. Other studies [11], [33] revealed that the AI production process has helped in the reduction of waste and energy by allocating resources by predicting resource needs during production (also referred to as pull principle). 
The advancement in technology has also led to the introduction of high-tech computing capabilities to digitally model manufacturing-design. Industries can use 3D printing to reduce excess production outputs and eliminate design waste [12]. Waste is minimised because of the precision in the production process. The use of 3D printing is not well reported in the literature reviewed. The reason for this could be because the use of 3D printing is still a growing concept in South African manufacturing [33]. Further investigation will help stakeholders to understand how 3D printing can change the dynamics of production in South Africa.

Technologies are drivers for industries to be more flexible and competitive in the utilisation of resources [14]. IoT is a key infrastructure for interconnecting elements of manufacturing to provide shared-based information between smart machines and people. It is creating a new trend in manufacturing, and is changing how resources are monitored and optimised and the way industries collaborate [16]. IoT fuses services and intelligence to foster a production process that ensures flexibility and resource efficiency. IoT has successfully been adopted for predicting natural disasters, climate change and water quality management [31]. IBM Smart planet initiatives, Microsoft eye-on-earth and HP are leading initiatives that utilise IoT for sustainability. South African manufacturing industries are using network technology combined with IoT to link production with supply and consumers [31]-[33]. The ability to interconnect production processes is making it possible to: (i) remotely access and manage machine plants thereby saving travel cost and time; (ii) reduce production waste; and (iii) support intelligent energy management and the use of renewable energy.

\subsection{ICT Driven SMP Initiatives and Limitations in South Africa}

South Africa is the leading manufacturing industry in the African region and has several promising manufacturing industries e.g. automobile, horticulture, garment and textile and consumer goods [12]. Government agencies, research institutes and private companies in the country have developed internal policies, strategies and programs to sustain the environment as a whole and the activities of manufacturing industries [22]. Global ecological sustainability and innovation policies are sometimes not applicable to the South African context because of the complexity of the policies. The inadequate use of ICT in South African manufacturing industries is a great concern, which is hindering the achievement of SMP in the country [20] and South African industries' effort to compete globally. Table 3 summarises the role of ICT in South African manufacturing industries and the constraints hindering the full implementation of ICT for SMP.

\begin{tabular}{|c|c|c|}
\hline ICT driven SMP & STRATEGY & CONSTRAINTS \\
\hline $\begin{array}{l}\text { Smart production } \\
\text { systems }\end{array}$ & $\begin{array}{l}\text { Reduce waste, time \& } \\
\text { cost of production }\end{array}$ & $\begin{array}{ll}\text { - } & \text { Inadequate expertise to man } \\
\text { sophisticated tools }\end{array}$ \\
\hline Automation & $\begin{array}{l}\text { Automate production } \\
\text { processes }\end{array}$ & $\begin{array}{ll}\text { - } & \text { High cost of training } \\
\text { - } & \text { Legacy \& infrastructural }\end{array}$ \\
\hline $\begin{array}{l}\text { Smart production } \\
\text { using IoT }\end{array}$ & $\begin{array}{l}\text { Intelligent production } \\
\text { practices; market } \\
\text { preference \& } \\
\text { segmentation }\end{array}$ & $\begin{array}{l}\text { integration challenges } \\
\text { - } \quad \text { Security \& privacy concerns } \\
\text { - } \quad \text { Lack of standardisation in } \\
\text { practice and policies }\end{array}$ \\
\hline $\begin{array}{l}\text { Energy efficiency } \\
\text { systems }\end{array}$ & Reduce operation costs & \\
\hline $\begin{array}{l}\text { Sustainable } \\
\text { research activities }\end{array}$ & $\begin{array}{l}\text { Design of intelligent } \\
\text { production systems }\end{array}$ & dequate research funding \\
\hline
\end{tabular}

Table 3. Constraints to SMP- ICT Initiatives \& Strategies in South Africa

South African industries are making attempts to integrate technologies to reduce waste and to cut cost and time of production. These sustainable strategies have been successful because South African 
industries are leveraging the potentials of Industry 4.0 [15], [19]. However, stakeholders need to improve their strategies to compete globally. The limit to how ICT is used in manufacturing industries in South Africa is accorded to the lack of expertise to man the new technologies and the high cost of training employees [1], [32]. Small and Medium Enterprises (SMEs) are key players in the South African manufacturing economy and are often constrained by limited resources.

IoT is gaining significant interest in Africa and is transforming manufacturing industries and other sectors by creating new market segmentation and new consumer preferences. Users can manage their devices remotely, thereby revolutionising the industrial sector. Machines can now communicate and act intelligently. However, the slow deployment of modern networking technology i.e. IPv6 is slowing the adoption of IoT in Africa [23]. The lack of standardisation of the components, architecture, security guidelines, privacy policies and communication framework are also setbacks to the adoption of IoT in manufacturing industries [23], [30].

There is active ongoing research on technology for SMP in South African institutions. For example, Stellenbosch's Technology Centre's Laboratory for Advanced Manufacturing (STC-LAM) developed a visual management system to collect shop floor data for a decision support system [1]. Open Community Manufacturing (OCM) was initiated by the University of Johannesburg to bring to light hidden knowledge, which led to the development of a stove using an open design strategy [1]. Whilst some research is taking place, inadequate funding for research activities is slowing down innovation in South African institutions [23].

\section{Conclusion}

Sustainable manufacturing is trending as a global concern. South African institutions are making efforts to conserve resources to ensure that the ecosystem is not destroyed. Efforts are being put in place by industries to see that wastes are minimised, materials are re-used, and conservation practices are sustained. South African government agencies, communities, companies and individuals are making efforts toward sustainable development practices as social consciousness and environmental responsibility.

The manufacturing process is gradually transforming from the notion of changing raw materials into a new product to a more eco-centric process of producing materials by using recycled resources and optimising the conventional production process. Concepts like IoT, smart systems and intelligent systems are considered as the backbone of the modern manufacturing process. The manufacturing process has changed to a more sophisticated process of producing an individualised product by competing for ecological and technical resources.

South African industries are actively adopting ICT in manufacturing activities. This study identified the following from literature: (i) the use of ICT for automation in industries, (ii) the application of IoT in smart production processes, (iii) the identification of current research work towards ICT for sustainability, and (iv) stakeholders' efforts to efficiently use resources to achieve a sustainable strategy. The ESET model of four factors driving SMP is proposed, which extends previous models proposing only three factors. The next phase of this study will test the proposed model based on empirical studies and recommend improvement if necessary. This study recommends that further studies might provide more perspectives on the role of ICT in achieving SMP. The findings in this study are limited to the articles reviewed, the search parameters and the search engine used. Findings may differ if the database search is expanded to include elaborate terms. 


\section{References}

[1] A. Rebensdorf, A. Gergert, G. A. Oosthuizen, and S. Böhm, "Open community manufacturing Development Challenge as a concept for value creation for sustainable manufacturing in South Africa," in 12th Global Conference on Sustainable Manufacturing, 2015, vol. 26, pp. 167-172.

[2] A. Rowe, "ICT sustainability and being a sustainable business: an interview with Alison Rowe, Fujitsu," Carol Adams, 2013. .

[3] M. Ndubuaku and D. Okereafor, "Internet of Things for Africa: Challenges and Opportunities," vol. 9, no. November 2015, pp. 23-31, 2015.

[4] E. Borgia, "The internet of things vision: Key features, applications and open issues," Comput. Commun., vol. 54, pp. 1-31, 2014.

[5] H. Bhorat and C. Rooney, "State of Manufacturing in South Africa," 2017.

[6] T. Phillips, "Sustainable Development \& Environmental Awareness," Barlowood, 2007. [Online]. Available: http://www.enviropaedia.com/topic/default.php?topic_id=269. [Accessed: 10-Jan-2018].

[7] Y. Levy and T. J. Ellis, "Towards a Framework of Literature Review Process in Support of Information Systems Research," in Proceedings of the 2006 Informing Science and IT Education Joint Conference, 2006, pp. 171-181.

[8] V. Clarke and V. Braun, "Thematic analysis," Encyclopaedia of Quality of Life and Well-Being Research. Springer Netherlands, pp. 6626-6628, 2014.

[9] I. Adebayo Bello, M. N. bin Ismail, and N. A. Kabbashi, "Solid Waste Management in Africa: A Review," Int. J. Waste Resour., vol. 6, no. 2, pp. 1-4, May 2016.

[10] J. O. Adeoti, Technology and the Environment in Sub-Saharan Africa-Emerging Trends in the Nigerian Manufacturing Industry, vol. 136. Kenya, 2007.

[11] M. Bakkari and A. Khatory, "Industry 4.0: Strategy for more sustainable industrial development in SMEs," in 7th Annual Conference on Industrial Engineering and Operations Management, 2017, pp. 1693-1701.

[12] K. Banga and D. Willem Te Velde, "Digitalisation and the Future of Manufacturing in Africa," 2018.

[13] R. Berkowitz, "Sustainable manufacturing conference in South Africa highlights importance of materials," MRS Bulletin, vol. 42, no. 5, pp. 334-336, 2017.

[14] P. Butala, R. Vrabic, and G. Oosthurizen, "Distributed Manufacturing Systems and the Internet of Things: A Case Study," in SAIIE25 Proceedings, 2013, no. July, pp. 1-12.

[15] H. Christopher, "Automation and the Future of Labor in the South African Manufacturing Sector," 2018.

[16] L. Coetzee and J. Eksteen, "The Internet of Things - Promise for the Future? An Introduction," in ISTAfrica 2011 Conference Proceedings, 2011, vol. 73, pp. 1-9.

[17] R. Couth and C. Trois, "Sustainable waste management in Africa through CDM projects," Waste Manag., vol. 32, no. 11, pp. 2115-2125, 2012.

[18] J. F. W. Durr, D. Hagedorn-Hansen, and G. A. Oosthuizen, "Waste to Resource Process Chain Strategies for Global Manufacturers," in 14th Global Conference on Sustainable Manufacturing, GCSM 3-5 October 2016, 2017, vol. 8, no. 2017, pp. 595-602.

[19] R. Girdwood, M. Bezuidenhout, P. Hugo, P. Conradie, G. Oosthuizen, and D. Dimitrov, "Investigating Components Affecting the Resource Efficiency of Incorporating Metal Additive Manufacturing in Process Chains," 14th Glob. Conf. Sustain. Manuf. GCSM 3-5 Oct. 2016, vol. 8, no. 2017, pp. 52-58, 2017.

[20] N. S. Madonsela, P. Mbecke, and C. Mbohwa, "Improving The South African Manufacturing Sector's Competitiveness through the Adequate Use of ICT," in International Conference on Information Technology and Computer Systems Engineering (ITCSE'2013) Nov. 27-28, 2013, pp. 69-73.

[21] P. T. Mativenga, J. Agwa-Ejon, C. Mbohwa, A. A. M. Sultan, and N. A. Shuaib, "Circular Economy Ownership Models: A view from South Africa Industry," in 14th Global Conference on Sustainable Manufacturing, GCSM 3-5 October 2016, 2017, vol. 8, no. 2017, pp. 284-291.

[22] C. Moses, "Eco-innovation in South African manufacturing enterprises: Trends and benefits," 2017.

[23] J. Murumba and C. Kiarie, "IoT as a Catalyst for Techno-innovation in Africa," Res. Acies Int. J. Comput. Knowl. Manag., vol. 1, no. 1, pp. 20-31, 2018.

[24] M. Mutingi, H. Musiyarira, C. Mbohwa, and V. P. Kommula, "An Analysis of Enablers and Barriers of Sustainable Manufacturing in Southern Africa," in Proceedings of the World Congress on Engineering and Computer Science, 2017, vol. II, pp. 25-28.

[25] B. G. Mwanza and C. Mbohwa, "Drivers to Sustainable Plastic Solid Waste Recycling: A Review," in 
14th Global Conference on Sustainable Manufacturing, GCSM 3-5 October 2016, 2017, vol. 8, no. 2017, pp. 649-656.

[26] B. G. Mwanza and C. Mbohwa, "Major Obstacles to Sustainability in the Plastic Industry," in 14th Global Conference on Sustainable Manufacturing, GCSM 3-5 October 2016, 2017, vol. 8, no. 2017, pp. 121128.

[27] B. G. Mwanza, C. Mbohwa, and A. Telukdarie, "Strategies for the Recovery and Recycling of Plastic Solid Waste (PSW): A Focus on Plastic Manufacturing Companies," in 15th Global Conference on Sustainable Manufacturing, 2018, vol. 21, no. 2018, pp. 686-693.

[28] A. Z. Nissinoff, "An Investigation of the Role of the Chinese Private Sector in the Establishment of Sustainable Apparel Manufacturing in Sub-Saharan Africa,” Soc. Impact Res. Exp., vol. 52, 2017.

[29] J. Ogbemhe, K. Mpofu, and N. S. Tlale, "Achieving Sustainability in Manufacturing Using Robotic Methodologies," in 14th Global Conference on Sustainable Manufacturing, GCSM 3-5 October 2016, 2017, vol. 8, no. 2017, pp. 440-446.

[30] R. Provinah, "Smart Africa: Patents and Standards in ICT, a roadmap for Africa in the digital world," Uppsala Univesitet, 2017.

[31] L. P. Steenkamp, D. Hagedorn-Hansen, and G. A. Oosthuizen, "Visual Management System to Manage Manufacturing Resources," in 14th Global Conference on Sustainable Manufacturing, GCSM 3-5 October 2016, 2017, vol. 8, no. 2017, pp. 455-462.

[32] M. W. Waibel, L. P. Steenkamp, N. Moloko, and G. A. Oosthuizen, "Investigating the Effects of Smart Production Systems on Sustainability Elements," in 14th Global Conference on Sustainable Manufacturing, 2017, vol. 8, no. 2017, pp. 731-737.

[33] M. W. Waibel, G. A. Oosthuizen, and D. W. Du Toit, "Investigating current smart production innovations in the machine building industry on sustainability aspects," in 15th Global Conference on Sustainable Manufacturing, 2018, vol. 21, no. 2018, pp. 774-781.

[34] P. De Wet, G. A. Oosthuizen, J. F. Oberholzer, M. D. Burger, and C. I. Ras, "Evaluation of Resource Efficient Process Chains for Secondary Manufacturing Processes of Bamboo Bicycles," 14th Glob. Conf. Sustain. Manuf. GCSM 3-5 Oct. 2016, vol. 8, no. 2017, pp. 44-51, 2017.

[35] G. Oosthuizen, R. F. Laubscher, N. Tayisepi, and J. Mulumba, "Towards Energy Management during the Machining of Titanium Alloys," in SAIIE25 Proceedings, 2013, no. July, pp. 1-14. 